\title{
Compliance to prenatal iron and folic acid supplement and associated factors among women during pregnancy in south east Ethiopia: a cross- sectional study
}

\begin{abstract}
Background: Nutritional anemia is one of the leading causes of morbidity and mortality among pregnant women in developing country. Several studies have shown that prenatal iron and folic acid supplement for three months and more during pregnancy plays a great role in preventing maternal morbidity and mortality. The aim of this study was to assess compliance of prenatal iron and folic acid supplement and its associated factors during Antenatal Care in Goba District South East Ethiopia.
\end{abstract}

Methods: A community based cross-sectional study was conducted from March to May, 2014 in Goba District. A total of 405 mothers who gave birth in the last six months were selected using systematic random sampling technique. Data were collected using pretested questionnaire by interview and then entered and analyzed using SPSS version 20. Both bivariate and multivariate logistic regression were carried out to see significant association. Variables with P-value less than 0.05 were considered as significant in the multivariate analysis

Results: The compliances rate to IFA supplement was found out to be $18 \%$. Educational status of mother $(\mathrm{AOR}=0.24(95 \% \mathrm{CI} 0.63-0.97))$, knowledge on anemia $(\mathrm{AOR}=0.41(95 \%$ CI $0.20-0.84)$ ), knowledge on benefit of iron folic acid (AOR $=0.38$ (95\% CI $0.20-0.77$ ), receiving health education on IFA supplement during prenatal visit $(\mathrm{AOR}=4.03(95 \% \mathrm{CI}$ 1.4-11.5) were found to be factors associated with compliances to iron folic acid supplement

Conclusion: Compliance to IFA supplement was low among the study communities. Improving awareness of the community about IFA supplement during pregnancy and improving educational status of women are highly recommended.

Keywords: iron, folic acid, compliances to IFA, women, southeast Ethiopia
Volume 7 Issue 2 - 2017

\author{
Mekonnen Tegegne Haile,' Abera Biratu \\ Jeba,' Mohammedawel Abduku Hussen² \\ 'Department of Nursing, Madda Walabu University, Ethiopia \\ ${ }^{2}$ Department of Midwifery, Madda Walabu University Goba \\ Referal Hospital, Ethiopia
}

Correspondence: Mekonnen Tegegne Haile, Department of Nursing, College of Medicine and Health Sciences, Madda Walabu University, Bale Goba, Ethiopia, Email tegegnemekonnen19@gmail.com

Received: July 19, 2017 | Published: November 0I, 2017
Abbreviations: ANC, antenatal care; EDHS, Ethiopian demographic and health survey; IDA, iron deficiency anemia; IFA, iron/folic acid; MMR, maternal mortality rate; NIE, nutritional initiative of Ethiopia; PNC, postnatal care; SPSS, statistical package for social science; WHO, world health organization

\section{Background}

Anemia is a global public health problem affecting two billion people worldwide. Globally, $41.8 \%$ of pregnant women and $30.2 \%$ of non-pregnant women are anaemic. ${ }^{1}$ At least half of this anemia burden is assumed to be due to iron deficiency. ${ }^{2}$ Many studies documented the adverse effects of maternal anemia, $12.8 \%$ and $3.7 \%$ of maternal mortality in Asia and Africa respectively is directly attributable to anemia. ${ }^{3}$ In Ethiopia, anemia is the severe problem affecting $62.7 \%$ of pregnant mothers and $52.3 \%$ non-pregnant women., ${ }^{4,5}$ During pregnancy anemia have negative consequence both for mother and the infant. For mother, the consequences of anemia include reduced energy and capacity for work poor pregnancy and birth outcomes including premature delivery, low birth weight, and increased prenatal mortality and increased risk of death during delivery and postpartum.
It is estimated that as many as $20 \%$ of maternal deaths are caused by anemia and that anemia may be an associated cause in as many as $50 \%$ of maternal deaths worldwide. ${ }^{6}$

As a public health measure, iron/ folic acid supplementation has been the recommended strategy for alleviating anemia in pregnant women. WHO recommended daily dose of $30-60 \mathrm{mg}$ of elemental iron and $400 \mu \mathrm{g}(0.4 \mathrm{mg})$ Folic acid on daily bases throughout pregnancy. ${ }^{7}$

To combat Iron deficiency anemia, many developing countries including Ethiopia have interventions and programme during pregnancy. Provision of IFA supplement to all pregnant women free of charge is among the key interventions. The recommended dose by the Ministry of Health in Ethiopia is $60 \mathrm{mg}$ /day for 90days for iron and $400 \mu \mathrm{g}$ of folic acid daily. ${ }^{8,9}$ And, Although National Nutrition Strategy adopted key target of increasing the proportion of mothers who get IFA for more than 90days during pregnancy and the post-partum period to $50 \%$ by 2015 , there is discrepancy in the ANC coverage and the IFA intake level. The 2011 DHS documented IFA supplement of $17 \%$. More importantly the IFA intake 90 or more tablets found to be $0.4 \% .{ }^{10}$ Gastrointestinal side effects, inadequate supply of tablets, 
inadequate counselling, poor utilization of prenatal health-care services, lack of knowledge and patient fears about the tablets affect women's perception regarding tablet use in many countries. ${ }^{11-13}$

Even though iron folic acid (IFA) Supplementation during pregnancy is among the methods to reduce maternal mortality, in Ethiopia the coverage is very low, in addition there are limited studies conducted on this topic. Therefore, the findings of this study will give valuable information on compliances of IFA and its determinate factors for policy makers and service providers.

\section{Materials and methods}

A community based cross-sectional study using quantitative methods of data collection was conducted in Goba District, South East Ethiopia from March to May 2014. Those postnatal mothers who gave birth 6months before the survey were included in the study. The sample size for this study was determined using a single population proportion formula estimation, with the assumptions of; an expected compliances to IFA $50 \%$, a $95 \%$ confidence level, a $5 \%$ margin of error and a none response rate of $10 \%$. The final calculated sample size was 422 .

Goba district is divided into 2 urban and 24 rural kebeles (the smallest administrative unit in Ethiopia). From the district's 24 rural kebeles 4 was selected randomly and from the 2 urban kebeles 1 is selected randomly. In selected kebeles, preliminary survey was conducted to identify households with mothers who have child birth within 06months prior to the study and sampling frame was developed. After the total sample size was allotted proportionally to the selected kebeles based on the total number of deliveries in the past 06 months, respondents were selected using systematic random sampling technique.

Data was collected using semi-structured, interviewer administered, pretested questionnaire after obtaining informed consent. The completed questionnaire were given codes, checked for completeness and consistencies then entered into EPI-info version 3.5.3 statistical software and then transferred to SPSS version 20 statistical package for further analysis. Data cleaning were performed to check for accuracy and consistencies, missed values and variables were also checked and corrected. The results were presented in the form of tables, figures, and text.

In this study, women were categorized as compliant to IFA supplement if they took 90 or more IFA tablets on daily base during her pregnancy. ${ }^{14}$ Mother's knowledge of anemia was assessed using 20 questions. The questionnaire were composed of cause, health consequence, risk group and method of prevention in anemia, mothers who score mean value and above were considered as having good knowledge of anemia.

To assess mother's knowledge of IFA, 12 questions were employed, mothers who score mean value and above were considered as having good knowledge of IFA. Both bivariate and multivariate logistic regressions were used to identify factors associated with compliances to IFA. Odds ratio with $95 \%$ confidence interval was used to identify the presence and strength of association between variables.

Ethical clearance was obtained from the Institutional Ethical Review Board of Institute of Public Health, College of Medicine and Health Sciences, University of Gondar. Correspondingly written letters were offered from Bale Zone Health Department. Finally informed consent was obtained from each mother before the start of the interview.

\section{Results}

\section{Socio-demographic characteristics}

A total of 405 PNC mothers who give birth 6months before data collection were included in the study with a response rate of $95.9 \%$. The mean age of the respondents was $26.3( \pm 5.1)$ years. Around $35.6 \%$ of respondent were in age group of $21-25$ years and about $28 \%$ were in age group of 36-40years.

Majority of the women interviewed were married (98.1\%) and rural dwellers (83.2\%). About (32.1\%) of the respondents were unable to read and write, $(27.4 \%)$ can only read and write, $(13 \%)$ had primary school level and (19.5\%) had secondary school level. Regarding occupation majority of the respondents were house wives $(72.6 \%)$ (Table1).

\section{Pregnancy and obstetric related characteristic of respondent}

Around half of the respondents had less than three times ANC visit. Around eleven percent of the respondents had history of abortion and $3 \%$ had history of still birth. Among the respondents $21.7 \%$ started ANC while their pregnancy was less than 12 weeks of gestation, and $26.7 \%$ started after 24 weeks of gestation (Table 2).

\section{Respondent's knowledge about anemia and benefit of IFA supplement}

Two third (62.5\%) of respondents had good knowledge on cause, consequence, risk group, and method of prevention in anemia, while $60.7 \%$ of the respondents had good knowledge on benefits of IFA (Table 3).

\section{Service related characteristics}

About $78.9 \%$ were provided with health education and $21.2 \%$ were not provided health education on iron/folic acid supplements during their IFA collection. . Regarding dispensing of supplement; majority of the respondents $(87 \%)$ collected 30 tablets whereas $12.8 \%$ were collected more than 30 tablets per visit (Table 4).

\section{Compliances to iron/ folic acid supplement}

It was found out that only $18 \%$ of the respondents were compliant to iron/folic acid supplement (Figure 1).

\section{Factors associated with adherence}

Bivariate analysis for compliances to IFA revealed that place of residence, educational status of mother, education level of the husband, mothers knowledge of anemia, mothers knowledge on benefits of iron folic acid and receiving health education at the time of supplement collection have significant association with compliance to IFA at $\mathrm{p}$ value $\leq 0.02$.

Multivariable logistic regression was done to control potential confounders and educational status of mother, knowledge on anemia, knowledge on benefits of iron folic acid and receiving health education at the time of supplement collection have significant association with compliances to IFA at $p$ value $\leq 0.05$ (Table 5). 
Table I Socio-demographic and economic characteristics of respondent of pregnant and PNC mothers, Goba Woreda, South East Ethiopia, 20 I4 ( $\mathrm{n}=405$ )

\begin{tabular}{|c|c|c|c|}
\hline Variable & Category & Frequency & Percent \\
\hline \multirow{5}{*}{ Age } & $16-20$ & 51 & 12.6 \\
\hline & $21-25$ & 144 & 35.6 \\
\hline & $26-30$ & 132 & 32.6 \\
\hline & $31-35$ & 50 & 12.3 \\
\hline & $36-40$ & 28 & 6.9 \\
\hline \multirow{4}{*}{ Marital Status } & Single & 15 & 3.7 \\
\hline & Married & 370 & 91.3 \\
\hline & Divorced & 4 & 1 \\
\hline & Widowed & 16 & 4 \\
\hline \multirow{4}{*}{ Religion } & Orthodox & 174 & 43 \\
\hline & Catholic & 6 & 1.5 \\
\hline & Muslim & 213 & 52.5 \\
\hline & Protestant & 12 & 3 \\
\hline \multirow{2}{*}{ Residence } & Rural & 337 & 83.2 \\
\hline & Urban & 68 & 16.8 \\
\hline \multirow{3}{*}{ Family Size } & $<4$ Family & 71 & 17.5 \\
\hline & 4-7 Family & 253 & 62.5 \\
\hline & $>7$ Family & 81 & 20 \\
\hline \multirow{6}{*}{ Educational Level } & Can $t$ read and write & 122 & 30.1 \\
\hline & Can read and write & 117 & 28.9 \\
\hline & Primary & 53 & 13.1 \\
\hline & Secondary & 84 & 20.7 \\
\hline & Above Secondary & 29 & 7.2 \\
\hline & House Wife & 294 & 72.6 \\
\hline \multirow{5}{*}{ Occupation of Mother } & Governmental Employee & 41 & 10.1 \\
\hline & Private Employee & 18 & 4.4 \\
\hline & Daily Labourer & 11 & 2.7 \\
\hline & Merchant & 24 & 5.9 \\
\hline & Farmer & 17 & 4.3 \\
\hline \multirow{5}{*}{ Educational Level of Husband } & Can T Read and Write & 80 & 19.8 \\
\hline & Can Read and Write & 116 & 28.6 \\
\hline & Primary & 59 & 14.6 \\
\hline & Secondary & 117 & 28.9 \\
\hline & Above Secondary & 33 & 8.1 \\
\hline \multirow{5}{*}{ Occupation of Husband } & Governmental Employee & 58 & 14.3 \\
\hline & Private Employee & 47 & 11.6 \\
\hline & Daily Labourer & 12 & 3 \\
\hline & Merchant & 27 & 6.7 \\
\hline & Farmer & 261 & 64.4 \\
\hline
\end{tabular}


Table 2 Pregnancy and obstetric related characteristic of respondent Goba woreda, Oromia region, South East Ethiopia, 20 I4 $(n=405)$

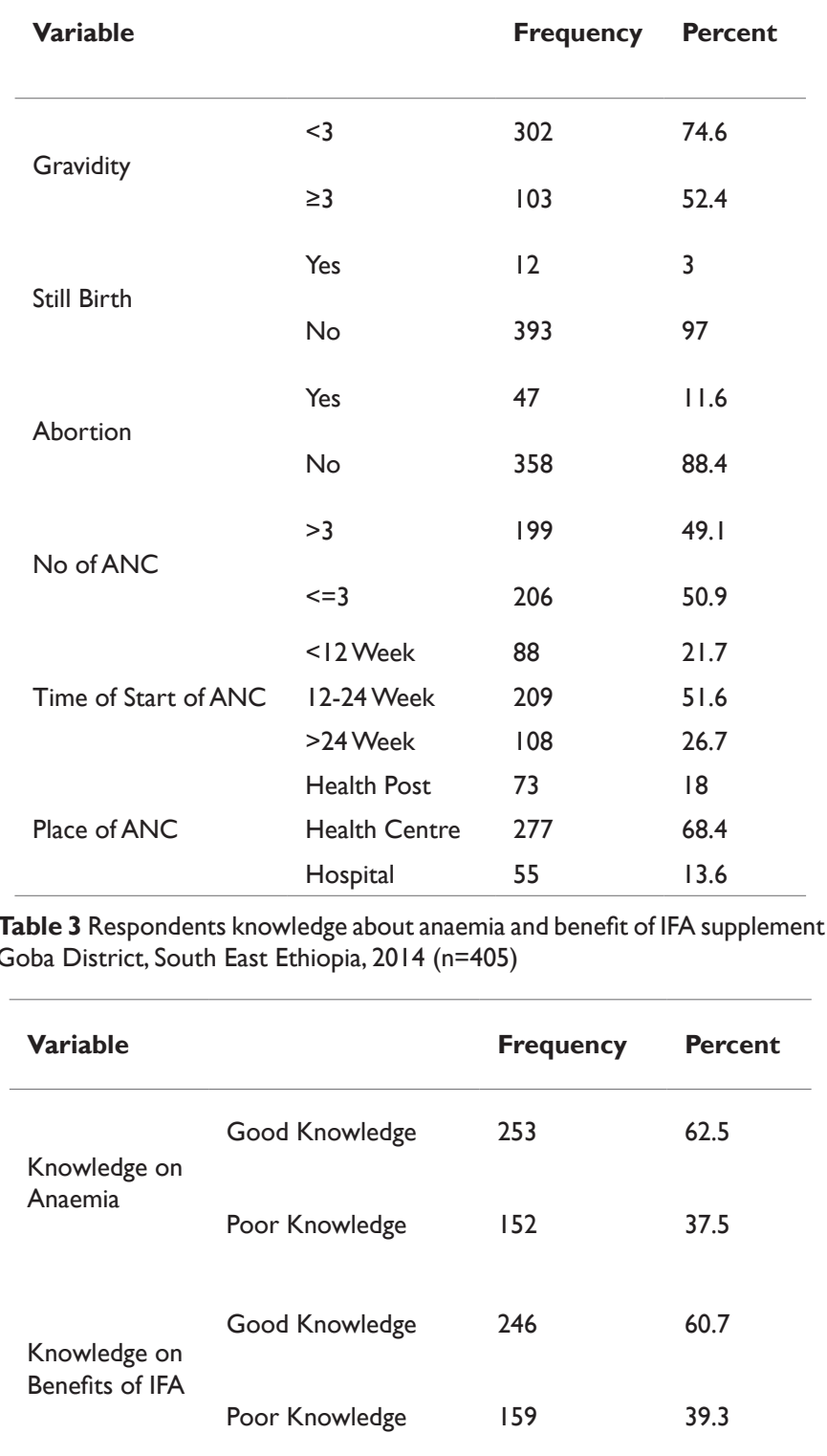

Table 4 Service related characteristics Goba District, South East Ethiopia, $2014(n=405)$

\begin{tabular}{|c|c|c|c|}
\hline Variable & Category & Frequency & Percent \\
\hline & Yes & 319 & 78.8 \\
\hline \multicolumn{4}{|c|}{ Health Education } \\
\hline & No & 86 & 21.2 \\
\hline & $<30$ minute & 354 & 87.4 \\
\hline \multicolumn{4}{|c|}{ Waiting Time } \\
\hline & $>30$ minute & 51 & 12.6 \\
\hline & Yes & 93 & 23 \\
\hline \multicolumn{4}{|c|}{ Problem Faced } \\
\hline & No & 312 & 77 \\
\hline \multirow{2}{*}{$\begin{array}{l}\text { Number of Tab } \\
\text { Supplemented PerVisit }\end{array}$} & 30 tab & 353 & 87.2 \\
\hline & $>30$ tab & 52 & 12.8 \\
\hline
\end{tabular}

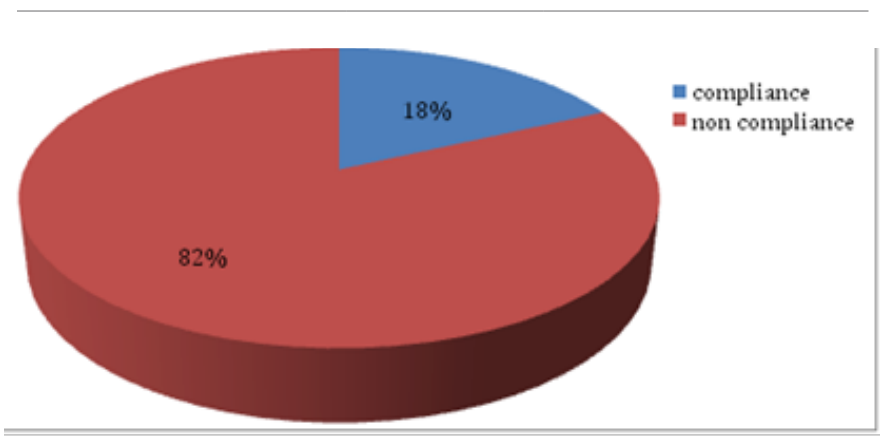

Figure I Adherence level of mothers to IFA Goba District South East Ethiopia, 2014.

Table 5 Factor associated with compliance to IFA at Goba District, South East Ethiopia, $2014(n=405)$

\begin{tabular}{|c|c|c|c|c|c|}
\hline \multirow{2}{*}{ Factors } & \multirow{2}{*}{ Category } & \multicolumn{2}{|c|}{$\begin{array}{l}\text { Compliance status of } \\
\text { respondent }\end{array}$} & \multirow{2}{*}{$\begin{array}{l}\text { COR }(95 \% \\
\text { CI) }\end{array}$} & \multirow{2}{*}{$\begin{array}{l}\text { AOR }(95 \% \\
\text { CI) }\end{array}$} \\
\hline & & Compliance & $\begin{array}{l}\text { Non- } \\
\text { compliance }\end{array}$ & & \\
\hline \multirow{2}{*}{ Place of Residence } & Rural & 54 & 283 & $\begin{array}{l}0.49(0.26 \\
0.90)\end{array}$ & $0.69(0.3 \mathrm{I}, \mathrm{I} .5)$ \\
\hline & Urban & 19 & 49 & 1 & I \\
\hline \multirow{5}{*}{ Educational Status of Mother } & $\begin{array}{l}\text { Can t Read and } \\
\text { Write }\end{array}$ & 9 & 113 & $.20(0.7,0.60)$ & $\begin{array}{l}0.1 I(0.026 \\
0.47)\end{array}$ \\
\hline & $\begin{array}{l}\text { Can Read and } \\
\text { Write }\end{array}$ & 20 & 97 & $.54(.21,1.39)$ & $\begin{array}{l}0.23(0.064, \\
0.87)\end{array}$ \\
\hline & Primary Education & 8 & 45 & $0.46(0.15-1.4)$ & $\begin{array}{l}0.24(0.63 \\
0.97)\end{array}$ \\
\hline & $\begin{array}{l}\text { Secondary } \\
\text { Education }\end{array}$ & 28 & 56 & $\begin{array}{l}\text { I.3I }(0.5 \mid \\
3.33)\end{array}$ & $0.97(0.32,2.8)$ \\
\hline & Above Secondary & 8 & 21 & I & I \\
\hline
\end{tabular}

Citation: Haile MT, Jeba AB, Hussen MA. Compliance to prenatal iron and folic acid supplement and associated factors among women during pregnancy in south east Ethiopia: a cross-sectional study.J Nutr Health Food Eng. 2017;7(2):272-277. DOI: 10.15406/jnhfe.2017.07.00235 


\begin{tabular}{|c|c|c|c|c|c|}
\hline \multirow{2}{*}{ Factors } & \multirow{2}{*}{ Category } & \multicolumn{2}{|c|}{$\begin{array}{l}\text { Compliance status of } \\
\text { respondent }\end{array}$} & \multirow{2}{*}{$\begin{array}{l}\text { COR }(95 \% \\
\text { Cl) }\end{array}$} & \multirow{2}{*}{$\begin{array}{l}\text { AOR }(95 \% \\
\text { CI) }\end{array}$} \\
\hline & & Compliance & $\begin{array}{l}\text { Non- } \\
\text { compliance }\end{array}$ & & \\
\hline \multirow{5}{*}{ Educational Status of Husband } & $\begin{array}{l}\text { Can } \mathrm{t} \text { Read and } \\
\text { Write }\end{array}$ & 10 & 70 & $\begin{array}{l}0.38(0.13 \\
1.04)\end{array}$ & I.3I $(0.34,4.9)$ \\
\hline & $\begin{array}{l}\text { Can Read and } \\
\text { Write }\end{array}$ & 16 & 100 & $\begin{array}{l}0.42(0.16 \\
1.08)\end{array}$ & $1.30(0.37,4.4)$ \\
\hline & Primary Education & 13 & 46 & $\begin{array}{l}0.75(0.28 \\
2.75)\end{array}$ & $3.3(0.90,12.3)$ \\
\hline & $\begin{array}{l}\text { Secondary } \\
\text { Education }\end{array}$ & 25 & 92 & $\begin{array}{l}0.72(0.29 \\
1.75)\end{array}$ & $0.85(0.30,2.3)$ \\
\hline & Above Secondary & 9 & 24 & I & 1 \\
\hline \multirow{2}{*}{ History of Abortion } & Yes & 15 & 32 & $2.4(1.23,4.7)$ & $\begin{array}{l}3.79(1.68 \\
8.55)\end{array}$ \\
\hline & No & 58 & 300 & I & 1 \\
\hline \multirow[b]{2}{*}{ Knowledge on Anemia } & Good & 58 & 195 & I & 1 \\
\hline & Poor & 137 & 15 & $\begin{array}{l}0.36(0.20 \\
0.67)\end{array}$ & $\begin{array}{l}0.4 I(0.20 \\
0.84)\end{array}$ \\
\hline \multirow[b]{2}{*}{ Knowledge on Benefits of Iron Folic Acid } & Good & 56 & 190 & I & 1 \\
\hline & Poor & 17 & 142 & $\begin{array}{l}0.40(0.22 \\
0.72)\end{array}$ & $\begin{array}{l}0.38(0.20 \\
0.77)\end{array}$ \\
\hline \multirow{2}{*}{$\begin{array}{l}\text { Health Education at the Time of Supplement } \\
\text { Collection }\end{array}$} & Yes & 68 & 251 & $4.3(1.71,11.2)$ & $4.03(1.4,11.5)$ \\
\hline & No & 5 & 81 & I & 1 \\
\hline
\end{tabular}

\section{Discussion}

This study revealed that only $18 \%$ of the studied subjects were compliant to IFA supplement. The compliance rate of this study is lower than a study conducted in Kenya $\left(24.5 \%,{ }^{15}\right.$ study conducted in Cambodia $(47 \%)^{16}$ and study conducted in India $(35.5 \%) .{ }^{17}$ This could be due to differences in socioeconomic status of the study population. But the finding of this study is higher than EDHS 2011 which was $0.4 \%$. This could be because of the present study has been conducted among ANC follower and the time gap between the present study and EDHS 2011..$^{18}$

Educational status of mother was an important socio demographic factor which showed significant association. The compliance rate of IFA supplement was significantly increases with educational status of mother. Mothers who can't read and write were $91 \%$, mothers who can read and write were $77 \%$ and mothers who had primary education were $76 \%$ less likely to adhere to IFA when compared with those who had above secondary education. This might be because, when women are educated, they might have accessible to information and advices from different sources about IFA and threats of anemia.

Another important variable that showed a significant association is knowledge of cause, consequences, risk group and method of prevention of anemia. The rate of compliance to IFA was $59 \%$ times less likely among women with poor knowledge.

This finding was similar with the study done in Nepal which identifies high proportion of compliances among pregnant mothers with good knowledge. ${ }^{19}$ This could be due to reason that knowledge of pregnant women about anemia related to causes, consequence and method of prevention affect their compliance of IFA. In addition good level of knowledge about anemia was a factor which could promote individuals in preventing iron deficiency anemia and following recommendation.

It was found out that there was a significant association between respondent's knowledge on benefit of IFA and compliance to IFA. Women with poor knowledge on benefit of IFA were $62 \%$ times less likely to adhere than women's with good knowledge on benefit of IFA. This could be due to the fact that good levels of knowledge promote mothers to take the supplements based on the recommendation. Receiving health education during prenatal visit was also an important predictor of compliance to iron folate supplements. This study showed that mothers who were provided with health education at the time of receiving supplements have about 4.03 (AOR 4.03 (95\% CI 1.411.5) times more likely to adhere to IFA supplement than those who were not provided. This could be due to the fact that health education at the time of supplement provides important information of IFA supplement.

\section{Conclusion}

Compliance to IFA supplements was low among pregnant women attending ANC in the study communities. Increase awareness of the community about anemia and IFA supplement during pregnancy, improving educational status of women, providing alternative community based delivery mechanisms and sustainable supply of IFA is highly recommended.

\section{Authors' contributions}

MT made substantial contributions in conception, design, and acquisition of data, analysis and interpretation of data and has been involved in drafting the manuscript. $\mathrm{AB}$ Participated in the design of the study, writing of results and discussion and has been involved 
in drafting the manuscript. MA Approved the proposal with some revisions: All authors read and approved the final manuscript. MT wrote the paper.

\section{Acknowledgements}

We would like to thank University of Gondar for approval of ethical clearance and technical and financial support for this study. We also acknowledge all staff of Institute of Public Health for their help and courage.

We would also like to extend our appreciation to, Bale Zonal Health Department and Goba District Health Office for providing the necessary information and facilitating conditions while carrying out this study. Above all our heartfelt thanks go to study participants who spent their precious time in responding to our questionnaire. All data collectors and the supervisors are highly acknowledged for the utmost effort they put to the quality of this research.

\section{Conflict of interest}

The author declares no conflict of interest.

\section{References}

1. Benoist Bd, McLean E, Egll I, et al. Worldwide prevalence of anaemia 1993-2005: WHO global database on anaemia. World Health Organization; 2008

2. Proposed global targets for maternal, infant, and young child nutrition. Summary of main issues raised and WHO responses Geneva. World Health Organization; 2012.

3. Khan KS, Wojdyla D, Say L, et al. WHO analysis of causes of maternal death: a systematic review. Lancet. 2006;367(9516):1066-1074.

4. Tarekegn SM, Lieberman LS, Giedraitis V. Determinants of maternal health service utilization in Ethiopia: analysis of the 2011 Ethiopian Demographic and Health Survey. BMC Pregnancy Childbirth. 2014;14:161.

5. Benson T, Bellete S, Chanyalew D, et al. An assessment of the causes of malnutrition in Ethiopia. USA; International Food Policy Research Institute; 2005. p. 1-213.

6. Idowu O, Mafiana C, Dopu S. Anaemia in pregnancy: a survey of pregnant women in Abeokuta, Nigeria. Afr Health Sci. 2007;5(4):295299.
7. Stoltzfus RJ, Dreyfuss ML. Guidelines for the use of iron supplements to prevent and treat iron deficiency anemia. World Health Organization; 1998. $39 \mathrm{p}$.

8. Jennings J, Hirbaye M. Review of Incorporation of Essential Nutrition Actions into Public Health Programs in Ethiopia. The Food and Nutrition Technical Assistance, 2008. p. 1-25.

9. Haidar J. Prevalence of anaemia, deficiencies of iron and folic acid and their determinants in Ethiopian women. J Health Popul Nutr. 2010;28(4):359-368.

10. Benson T, Solomon B, Demiss C. Framework document for the national nutrition strategy of Ethiopia. 2005.

11. Rofail D, Colligs A, Abetz L, et al. Factors contributing to the success of folic acid public health campaigns. J Public Health (Oxf). 2012;34(1):90-99.

12. Sanghvi TG, Harvey PW, Wainwright E. Maternal iron-folic acid supplementation programs: evidence of impact and implementation. Food Nutr Bull. 2010;31(2 Suppl):S100-107.

13. Aguayo VM, Koné D, Bamba SI, et al. Acceptability of multiple micronutrient supplements by pregnant and lactating women in Mali. Public Health Nutr. 2005;8(1):33-37.

14. Federal Ministry of Health [FMOH]. Best practice, progress updates, initiatives and articles, special bulletin. 2012

15. Dinga LA. Factors Associated With Adherence To Iron/Folate Supplementation Among Pregnant Women Attending Antenatal Clinic At Thika District Hospital In Kiambu County, Kenya. University of Nairobi; 2013.

16. Lacerte P, Pradipasen M, Temcharoen P, et al. Determinants of adherence to iron/folate supplementation during pregnancy in two provinces in Cambodia. Asia Pac J Public Health. 2011;23(3):315-323.

17. Jasti S, Siega-Riz AM, Cogswell ME, et al. Pill count adherence to prenatal multivitamin/mineral supplement use among low-income women. J Nutr. 2005;135(5):1093-1101.

18. Measure D, Macro I. Ethiopia Demographic and Health Survey 2011: Preliminary Report. Ethiopia: Central Statistical Agency; 2011.

19. Osrin D, Vaidya A, Shrestha Y, et al. Effects of antenatal multiple micronutrient supplementation on birthweight and gestational duration in Nepal: double-blind, randomised controlled trial. Lancet. 2005;365(9463):955-962. 